JITA: JH. Digital preservation.

\title{
POR UMA PRESERVAÇÃO INTEGRAL DA OBRA DE ARTE DIGITAL: ANOTAÇÕES SOBRE ARTE TECNOLÓGICA
}

\author{
FOR A COMPLETE PRESERVATION OF THE NEW MEDIA ART: \\ NOTES ON ART TECHNOLOGY \\ PARA UNA CONSERVACIÓN COMPLETA DE LA OBRA DE ARTE DIGITAL: \\ NOTAS SOBRE EL ARTE TECNOLÓGICO
}

Pablo Gobiral

\begin{abstract}
RESUMO
Este trabalho reflete sobre a arte digital e a sua preservação. Como uma arte reconhecida como nativa digital (born digital), ela se encontra entre o campo da arte contemporânea e o campo amplo da tecnologia digital. Ao mesmo tempo, ela se insere em uma sociedade na qual essa tecnologia se estabeleceu em todo o mundo possibilitando críticas à ideia do "digital" como avanço ou progresso. A partir desses pressupostos, procuramos pensar a complexidade dessa expressão artística manifesta na sua preservação. Neste artigo, que apresenta anotações derivadas de pesquisas sobre arte e a sua preservação, buscamos reunir a reflexão em torno das possibilidades do que poderia ser - e significar - uma preservação integral da arte digital.
\end{abstract}

PAlAVRAS-ChAVE: Artes digitais. Preservação digital. Preservação integral. Pós-digital. Arte e tecnologia.

\section{ABSTRACT}

This work discuss on digital art and its preservation. Being a kind of art recognized as born digital, it is among the field of contemporary art and the wide field of digital technology. At the same time, it is part of a society in which the technology has established itself worldwide providing means to criticize the idea of "digital" as advancement or progress. Based on those assumptions, we have tried to think about the complexity of that artistic expression which is manifested in its preservation. In this article, which features notes derived from research on art and its preservation, we seek to bring together the reflection on the possibilities of what could be - and mean - a complete preservation of digital art.

KEYWORDS: Digital arts; Digital preservation; Complete preservation; Post-digital; Art and technology.

\section{RESUMEN}

En este trabajo se refleja en el arte digital y su preservación. Como un arte reconocido como nativo digital (born digital), es entre el campo del arte contemporáneo y el amplio campo de la tecnología digital. Al mismo tiempo, es parte de una sociedad en la que esa tecnología se ha establecido en todo el mundo permitiendo una crítica a la idea de "digital" como avance o progreso. Partiendo de esas premisas, tratamos de pensar en la complejidad de esa expresión artística que se manifiesta en su preservación. En el presente artículo, que cuenta con notas derivadas de la investigación sobre el arte y su preservación, buscamos reunir a la reflexión sobre las posibilidades de lo que podría ser - y significar - una conservación integral del arte digital.

PALABRAS ClAVE: Artes digitales; Conservación digital; Conservación completa; Posdigital; Arte y tecnologia.

\footnotetext{
1 Mestre e Doutor em Estudos Literários (UFMG). Professor da Escola Guignard (UEMG). Membro pesquisador e gestor de serviços da Rede Brasileira de Serviços de Promoção Digital do IBICT/MCTI. Belo Horizonte, MG. Email: pa.gobira@ gmail.com. ORCID: http://orcid.org/0000-0002-3054-2383.

Submetido em: 03/08/2016 - Aceito em: 15/09/2016.
} 


\section{INTRODUÇÃ̃}

A tecnologia digital vem, há algum tempo, influenciando diversos campos da vida humana. O campo artístico não é diferente. Com a relação constante entre "tecnologia digital" e a ideia de "avanço" ou "progresso" foi comum vermos no decorrer dos anos - após o seu advento - a junção do adjetivo "digital" a diversos substantivos. Assim, os jogos tornaram-se jogos digitais, o cinema tornou-se cinema digital, a cultura se torna cultura digital, além da arte também ser adjetivada como digital, especialmente no caso brasileiro.

A arte digital - também conhecida como arte de novas mídias (new media art), arte computacional e arte tecnológica - tem no Brasil um percurso de formação recente e muito curioso como campo. Arte digital não é sequer uma subárea nas Tabelas de Áreas do Conhecimento do Conselho Nacional de Desenvolvimento Científico e Tecnológico (CNPq) ou da Coordenação de Aperfeiçoamento de Pessoal de Nível Superior (CAPES) ${ }^{2}$. Ainda sobre o caso brasileiro, a opção pela expressão "arte digital" pode ser uma escolha política (em prol de políticas públicas para o campo), principalmente ao recordar que profissionais da área pleitearam junto ao Ministério da Cultura brasileiro a criação de um Colegiado Setorial de Arte Digital (GASPARETTO, 2014).

Além do interesse político e econômico geral em torno das tecnologias digitais, replicado no campo da arte, há um crescimento do interesse de pesquisadores pelos processos produtivos (de criação e de exposição) da arte digital. Pesquisadores e instituições passaram igualmente a enfocar o processo de arquivamento e conservação em todo o mundo (GOBIRA, MUCELLI, PROTA, 2014).

Como o que estamos tratando aqui como "arte tecnológica" ou "arte digital" é um campo amplo de possibilidades, poderíamos relacioná-la com a ideia de arte "nascida digital" (born digital). Essa relação não é determinista, tendo em vista o recente debate acerca das configurações de um contexto pós-digital (SANTAELLA, 2016; GOBIRA; MUCELLI, 2016). Assim, considera-se que estamos em um momento em que "digital" não pode ser aceito como sinônimo de "avanço" ou "progresso", mas uma característica técnica que determinado serviço ou produto carrega.

Além disso, pós-digital "em seu sentido simplificado descreve o estado bagunçado da mídia, artes e design depois de sua digitalização (ou ao menos a digitalização de aspectos cruciais dos canais através dos quais eles são comunicados)." (CRAMER, 2014, tradução nossa) Então, o pós-digital é um contexto em que as diversas mídias e tecnologias disponíveis podem conviver e serem escolhidas/trabalhadas/relacionadas. Por esse motivo, não faria mais

$2 \mathrm{Na}$ CAPES (http://www.capes.gov.br/avaliacao/instrumentos-de-apoio/tabela-de-areas-do-conhecimentoavaliacao) e no CNPq (www.cnpq.br/documents/10157/186158/TabeladeAreasdoConhecimento.pdf) a subárea mais próxima dentro da área de "artes" é: “artes do vídeo" (código 8.03.09.00-3).

\begin{tabular}{l|l|l|l|l|l|l} 
(C) Rev. Digit.Bibliotecon. Cienc. Inf. & Campinas, SP & v.14 & n.3 & p.501-514 & set/dez. 2016 & ISSN 1678-765X \\
\hline
\end{tabular} 
sentido a persecução das "novas" mídias no campo artístico considerando o uso do digital como promotor de "ações" disruptivas.

O pós-digital é caracterizado pelas desconfianças nessa tecnologia como "salvadora" da história, memória e cultura humanas. Essa dimensão crítica ao pensar o pós-digital, mais do que uma necessidade de abraçar simplesmente um novo conceito, permite leituras divergentes dos acontecimentos na sociedade, além de abrir caminho para epistemologias que tinham menos recepção ou eram questionadas: sejam as reflexões ontológicas de pensadores como Peter Sloterdijk (2012), ou o debate sobre o antropoceno (PARIKKA, 2016) sob a luz das tecnologias atuais.

Tendo em vista que a obra de arte digital não é apenas digital; que se mescla de hardware e softwares industriais e/ou exclusivamente criados para elas; que não é fácil de ser definida e nomeada; as perguntas que podemos fazer aqui são: deve-se preservar uma integralidade da obra? Justamente um tipo de obra que tem instabilidades diversas oriundas dos softwares e hardwares de sua composição? Devemos reconhecer uma "originalidade" na versão exposta pela primeira vez e, por isso, repeti-la? Ou devemos pensar que a integralidade da obra de arte digital está em sua composição estética como arte e que esta deva ser perseguida pelo curador/conservador?

Pretendemos trazer nas próximas páginas algumas reflexões relacionadas a uma possível preservação plena da arte não no intuito de solucionar as questões postas, mas buscando pensar seus pontos transversais gerados pelo pensamento sobre preservação dentro do campo de estudos da arte tecnológica em contexto pós-digital.

\section{DAS ARTES DO VÍDEO AOS DADOS?}

Em texto sobre arte e tempo, Boris Groys (2010, p. 125) mostra que há uma transformação no mundo artístico que permitiu a seguinte evolução: passamos a expor como obras de arte os "registros" da arte - que são ao mesmo tempo mídia e informação. Esse novo costume é instaurado com as artes do vídeo em que foi possível trazer para o espaço expositivo vídeos de performances, vídeos sobre processos produtivos dos artistas, vídeos sobre a vida do artista dentre outras experiências. Para Groys, esses exemplos apontam uma exposição da "documentação de arte" e não especificamente a exposição da arte de fato.

No campo da arte já nos acostumamos, através das décadas de convivência com a vídeo arte, com a exposição de documentação da arte. Desse modo, não estranhamos - no campo da arte digital - o caminho principal da preservação da obra se dar prioritariamente na conservação dos seus dados (informacionais/computacionais). Temos em vista que um dos estatutos da obra de arte em contexto contemporâneo é reconhecidamente o de um 
"documento" da arte (em obras, por exemplo, em que o artista visual recupera memórias suas e de terceiros ou apresenta processos de sua produção artística etc.) ${ }^{3}$.

Pensando ao lado de Arthur Danto (2006) sobre o mundo da arte, mas divergindo em essência, poderíamos dizer que o que a preservação da arte digital conserva como dados é - e não é - uma obra de arte instaurada em um "outro" mundo da arte. A transfiguração praticada pelo artista digital, identificada por Danto na transformação da imagem das Brillo Boxes (1964) de Andy Warhol em arte, não é a mesma, pois deixa a obra em um lugar cindido. Em certo sentido, quando comparamos as Brillo Boxes com a ideia de documentação apontada por Groys sobre a video art, poderíamos considerá-las um arquivamento de informações visuais de produtos/mercadorias em contexto artístico. O costume de "documentar" trazido pela arte do vídeo pode ser visto, portanto, nesse exemplo da arte da segunda metade do século XX.

As experiências da segunda metade do século XX, vistas com o advento da vídeo arte, podem ser reconhecidas como experiências de documentação, transformação da obra de arte em informação a ser exposta. A arte digital tem encontrado dificuldade em ser preservada para além da conservação apenas de seus dados. No contexto de seu arquivamento como dados (informacionais e/ou computacionais), a obra de arte é passível de ser reconhecida como similar a qualquer outra "coisa" ou "ação" documentável na sociedade, desde o registro de um nascimento ou até o nomear de um edifício.

É claro que, como visto nos parágrafos anteriores, há outras formas de se ver a obra de arte contemporânea sem pensá-la como dados. Assim, o campo artístico ainda sustenta seu sistema (CAUQUELIN, 2005, p. 14) e permite que pessoas continuem pensando, estudando, criando, vendendo e comprando o que se considera arte hoje. Porém, com a mudança das epistemes no contexto contemporâneo, bem como com a dificuldade em se delimitar os campos de conhecimento (por exemplo, arte - tecnologias da comunicação e informação) há dificuldades em se delimitar o que é a arte (para além das dificuldades "tradicionais" dessa delimitação).

Dito de outro modo: sabemos ser difícil - há ao menos dois séculos - dizer o que é e o que não é arte devido à multiplicação do sistema de produção artístico sob a influência das mudanças provocadas pela Revolução Industrial. Com o advento das artes do vídeo, e agora na relação ampliada entre as artes e as tecnologias, as dificuldades com delimitações se multiplicam. Essas dificuldades ficam mais explícitas quando pensamos a preservação da arte tecnológica a partir do contexto artístico e industrial.

\footnotetext{
${ }^{3}$ Ver, por exemplo, a exposição $O$ arquivo universal e outros arquivos (Centro Cultural Banco do Brasil, Rio de Janeiro, jul./set. 2003), de Rosângela Rennó, bem como outros trabalhos da artista.

\begin{tabular}{l|l|l|l|l|l|l} 
(C) Rev. Digit.Bibliotecon. Cienc. Inf. & Campinas, SP & v.14 & n.3 & p.501-514 & set/dez. 2016 & ISSN 1678-765X \\
\hline
\end{tabular}
} 


\section{A PRESERVAÇÃo dA ARTE TECNOLÓGICA}

Quando olhamos para a arte produzida em relação com as tecnologias digitais é sedutor se concentrar em seu aspecto puramente técnico (descrição do processo produtivo e uso de tecnologias). A sedução tem origem na necessidade de se observar esses aspectos tendo em vista que o curador/conservador das obras de arte digital tem que conhecer o processo produtivo e procurar formas diversas de conservá-la e, ao mesmo tempo, tornar aquela obra acessível ao público. Porém, essa sedução acaba levando o curador/conservador a escolher o caminho mais viável tecnicamente: o da preservação da obra enquanto dados, como documentação ou informação a serem arquivadas (GOBIRA, 2015).

A preocupação tem estado em tornar a obra acessível ao público de um acervo, mas como dados. Há um esquecimento da (ou despreocupação com a) dimensão expositiva da obra de arte em sua plenitude estética: seja ela interativa (em interação com o interator); física (à frente do visitante da exposição para ser tocada ou fruída de várias posições); ou em software (por exemplo: vista/escutada em realidade virtual) etc. Justamente a dimensão mais comentada das obras de arte tecnológicas - a dimensão do rendimento/performance provocada na relação entre obras e público ou máquina e público - é esquecida (ou abandonada) quando da emergência de sua preservação, tornando-se diagramas com as formas de interação ou uma mera descrição, tal como: "a interação se dá com o interator permanecendo frente à câmera que captura a posição do seu corpo e...".

Pensar uma preservação plena ou, como aqui se prefere referir a ela, integral requer um esforço de consideração da manifestação da obra como um fenômeno. Entendida como fenômeno, permite-se que a obra de arte seja sentida (COCCIA, 2010) do mesmo modo como é possível se sentir outras coisas no mundo. O caminho da preservação apresentado até o momento mostra que a dimensão sensível parece estar sendo suplantada pelo enfoque na quantificação da obra como dados (informacionais/computacionais). Porém, esquece-se que esses dados sobre a obra de arte carregam uma concentração do seu aspecto técnicodescritivo, uma das potências do sensível. Essa particularidade tem seu valor, mas não pode ser o único valor aceito no processo preservacionista.

Ao trilhar esse caminho de considerar a obra como dados (armazenáveis, quantificáveis, informacionais/computacionais), na preservação digital da arte digital, não a diferenciamos das outras coisas sensíveis no mundo. Essa cognição fica mais lúcida quando nos lembramos da dificuldade científica cada vez maior em se distanciar os campos de conhecimento (as ciências duras das sociais das biológicas etc.), bem como se manifesta na formação de novos campos.

A obra de arte digital como dados é uma dimensão concreta e aceita nos estudos do campo não apenas sobre a sua preservação, mas da sua compreensão como uma obra de arte que existe em uma condição "digital”. Temos reparado (inclusive já apontado em outros 
trabalhos: GOBIRA, 2015; GOBIRA; CORRÊA, 2016) que por muitas vezes somos levados a essa limitação da obra de arte ao reforçarmos o diálogo dela com as mídias digitais. Nesse ínterim, parece haver algumas escolhas que estão sendo feitas: caso o campo "arte" seja defendido, não se admite a obra como dados (ao menos não completamente); se não há apego ao campo e à "arte", é possível abandonar a concepção da arte como algo além dos dados e assumir estes como elementos de estudo. Mais especificamente: assumir o enfoque na informação e a sua estética; algo que até pode ser realizado partindo de discussões sobre a estética da informação, como a de Max Bense (2003).

Com esse debate, conseguimos começar a ver que a característica técnica - até então extremamente dominante, sobretudo, nos estudos da preservação - não pode sobrepor à característica estética oriunda da obra de arte. As características estéticas da obra de arte digital têm sido no mínimo deixadas de lado quando se pensa em preservação, especialmente quando se opta por preservar: descrições das obras; fotografias e vídeos das/sobre as obras; o código de algumas obras. E negligencia-se: a preservação da interação (do usuário/interator com a obra) tal como a obra foi exposta; os erros (glitches) que houveram (e haverão!) quando da exposição; dentre outros inúmeros elementos que compõem já reconhecidamente essa obra de arte digital que não se limita apenas ao "funcionar" de uma máquina ou à estabilidade de um código.

Desde Gobira e Corrêa (2016) a questão da preservação da obra de arte digital não apenas como informação vem nos chamando a atenção. Ao mesmo tempo em que há uma necessidade de se preservar, sabemos das dificuldades que a mídia digital impõe aos esforços dessa preservação trazendo o estudioso e o conservador para a escolha do caminho da guarda da obra como dados (informacionais/computacionais).

Ao fazê-lo, surgem alguns problemas abordados não em caminho decisivo, mas como abertura de discussões que provavelmente serão levantados por uma próxima geração de trabalhos acadêmicos que trilharão epistemes diversas. Um dos problemas é justamente o que apareceu acima: ao considerarmos que a obra de arte preservada como dados tem a potência de ser sentida, podemos ponderar que os dados estão se igualando a qualquer outra coisa no mundo. Ao reduzir (ou aumentar, dependendo do ponto de vista) a obra a dados, parece que retiramos dela (da obra de arte em geral) as suas distinções frente às outras coisas do mundo. Então, por que preservá-la?

\section{UMA PRESERVAÇÃo ALÉM dOS DADOS}

A arte digital, como temos tratado aqui, tem um campo amplo e diversas possibilidades de obras: desde apenas imagens digitais, concept art, ilustrações realizadas em 
meio digital, vídeos digitais etc.; até obras de arte que envolvem robótica, realidade virtual imersiva, interatividades variadas localizadas ou telemáticas etc.

O campo também apresenta uma variada e complexa gama de pré-requisitos a serem cumpridos para cada projeto preservacionista. Uma imagem digital realizada em determinado software demanda, para uma preservação técnica integral, no mínimo: a conservação de sistema operacional; do software utilizado para criar a imagem; de uma máquina para execução ou emulação do sistema operacional e do software utilizado; e a imagem propriamente (código da imagem salvo, possivelmente, em alguma extensão). Agora imaginemos uma obra de arte que se configure como uma instalação interativa que tenha projeção, interação por uma interface similar a de jogos, bem como um aparato físico similar aos de estruturas de automação (braços robóticos, por exemplo).

Para cada especificação de obra de arte digital demanda-se um tipo de tratamento técnico preservacionista. O tratamento técnico específico não será encontrado neste trabalho e ainda não foi suficientemente desenvolvido. Contudo, a sua necessidade tem sido ao menos sinalizada por estudos recentes (tal como vemos em: LA FERNA, 2016). A reflexão proposta esteve até aqui no interstício entre as necessidades de se pensar a preservação técnica para além da preservação dos dados/documentação da obra alcançando a sua configuração sensível como fenômeno.

Por compreender a existência de uma dimensão não apenas técnica, mas também estética da obra, optamos por pensar a preservação integral. Essa ideia, pela complexidade dos tipos de obras digitais, é extremamente difícil de ser até mesmo discutida na profundidade devida. Isso se deve a primeira onda de digitalização do mundo que foi vivenciada entre o final do século XX e primeira década do século XXI. Essa onda permanece em países que ainda se encontram em dificuldades no acesso às tecnologias digitais, mas é um caminho que aparenta ser inevitável e que fortaleceu a semântica do adjetivo "digital" como "avanço/evolução".

Quando mencionamos uma "digitalização do mundo" no parágrafo acima, essa compreensão tem repercussão no campo da preservação em geral. Ainda hoje se estuda, pesquisa e realiza mais a "digitalização" de obras, de documentos etc. do que se pensa sobre a integralidade da preservação dos nativos digitais ou das obras de arte tecnológica. Alia-se a essa necessidade máxima de digitalização a ideia de que com ela o acesso à obra ou ao documento será expandido a um público maior do que os visitantes de um acervo. O cuidado necessário que devemos ter é em compreender que a solução da digitalização de tudo para promoção do acesso não é única e/ou ideal para todos os casos.

A tendência a se pensar em "estoques" de informação (BARRETO, 1994), alavancado pelo campo da Ciência da Informação e com os processos e técnicas de digitalização, acaba por apenas - como o próprio termo e conceito de estoque revela - gerar acúmulo de 
informações variadas quando se abraça exclusivamente o elemento técnico. Esse caminho não é algo questionado aqui, pois, como afirmado acima, estamos em um fluxo de "digitalização do mundo" que parece inevitável ou até mesmo inquestionável. Porém, mesmo sem questioná-lo de imediato precisamos pensar se é realmente conveniente ter esse processo como via única, pois ele influencia todo um campo com terminologias e tendências.

No caso da arte em específico devemos pensar, por exemplo, da perspectiva de um curador de exposições de artes digitais. Daqui a alguns anos (e com a obsolescência programada não precisam ser muitos anos para esse cenário provável se manifestar) ele desejará refazer uma exposição de arte digital de determinado artista ou grupo de artistas. $\mathrm{O}$ que ele conseguirá expor ${ }^{4}$ ? Caso as opções de preservação da arte digital sejam pelos dados (informacionais/computacionais) ele conseguirá expor somente a documentação do software criado, fotos e vídeos da primeira exposição da obra, talvez alguns elementos do design de interação, talvez algumas imagens da interface da obra, enfim, elementos técnicos com o início de um aporte estético. Em outras palavras a potência do sensível que foi aquela obra. Dependendo das técnicas de preservação dos dados (e da especificidade da obra), com uma equipe técnica o curador poderá reconstituir a obra, emulá-la, migrá-la ou recriá-la.

As partes que compunham essas obras de arte conservadas como dados foram, em sua plenitude, descartadas tal como se faz de fato com hardwares e mídias de softwares obsoletos. Lembramos que em acervos é comum a prática do descarte, porém em acervos o descarte é ponderado. Nas opções que estão sendo discutidas e tomadas no arquivamento como dados há o risco do descarte de hardwares e softwares apontando para um único caminho: acervos novos e/ou já criados que recebem ou receberão a arte digital deve ampliar, desse modo, as possibilidades de recepção das obras.

Compreendemos que a obra de arte digital, composta por hardwares e softwares que se tornam obsoletos, traz como uma de suas características a efemeridade (GOBIRA, 2014). Ressaltamos que a opção por essa efemeridade, muitas vezes, não é parte da obra, mas um acaso com o qual tanto o artista quanto o curador da exposição trataram enquanto a obra foi exposta. Na preservação, seria ideal fazer conviver o "obsoleto" (da perspectiva da indústria) com o "atual" ou "high tech", pois as obras de arte são realizadas a partir de demandas estéticas próprias e não a partir do produto (hardware ou software) mais recente no mercado.

Com Florian Cramer vemos que o pós-digital, como momento em que o "digital" não lidera mais os anseios de "evolução" tecnológica da sociedade, permite que os "feitos" artísticos se misturem sem hierarquia entre o digital e o não-digital. Ao fazê-lo, o autor

\footnotetext{
${ }^{4}$ As outras técnicas já consolidadas para reestabelecer obras de arte digital que foram expostas são, além da documentação: a emulação; migração; e recriação (GOBIRA, 2015). A emulação pode ser realizada com apenas informações sobre a obra de arte digital. A migração pressupõe haver ao menos códigos e outros registros computacionais da obra. Já a recriação assume de fato o processo que está relacionado a toda a reexposição de obras de arte digital conservadas que é a de refazer aquilo que já foi exposto. Neste trabalho defendemos de maneira crítica (em crise!) que ao conservar o máximo possível da obra de arte tecnológica se estará permitindo um universo maior de escolhas para a formação de uma futura exposição.
}

\begin{tabular}{l|l|l|l|l|l|l} 
(C) Rev. Digit.Bibliotecon. Cienc. Inf. & Campinas, SP & v.14 & n.3 & p.501-514 & set/dez. 2016 & ISSN 1678-765X
\end{tabular} 
questiona a existência de uma "estética do digital" assumindo uma estética pós-digital, pois tudo o que perceptível é analógico e não digital ("sinais não-discretos como som e ondas de luz") (CRAMER, 2014, tradução nossa).

Em nenhum momento deste artigo tratamos da existência de uma estética do digital, mas se ela for defendida do modo como foi criticada por Cramer, esse é mais um ponto que aproxima as obras de arte dos produtos ordinários. Estaríamos diante de uma estética do digital que é orientada pelo digital, o mesmo digital que está presente a cada dia em todos lugares do mundo revelando um mundo estético digital. Parece que estamos diante da transformação dos elementos puramente técnicos da arte digital (transfigurados no processo de guarda/preservação em dados) em elementos estéticos informacionais.

Pensar assim não seria uma novidade, tendo em vista que a obra de arte digital tem uma característica diferente da perspectiva artística crítica que percorreu o século XX e ainda percorre o século XXI e é considerada como algo presente na "arte contemporânea": utilizam-se objetos industriais para intervenção (A fonte, de Marcel Duchamp e outros de seus ready-mades, por exemplo); e utiliza-se a publicidade para realizar colagens (no Dada e Surrealismo). Portanto, se no século XX os artistas optavam pelo uso de elementos do mercado/indústria como partes (ou o todo) de suas obras de arte, agora parece não haver muitas saídas para os artistas - sobretudo para os artistas que trabalham com a arte tecnológica - a não ser tratar como normal o uso de tais objetos.

Hoje a utilização de hardwares (desde computadores a sensores diversos) e softwares (desde as ferramentas para criação e edição de imagens aos ambientes de programação e linguagens variadas) oriundos da indústria é considerada corriqueira na criação da arte digital, inclusive nas experimentações dos artistas hacktivistas ${ }^{5}$ e seus grupos que militam em uma ação de reuso e recriação dos produtos das indústrias (sic).

Quando nos museus, em seus acervos e arquivos, realizarmos a preservação apenas dos dados, também não podemos perder de vista que estamos conservando uma dimensão claramente industrial das obras de arte. A arte digital tem uma dependência da indústria (GOBIRA, 2014) que não é suplantada com a negação da conservação das partes obsoletas da obra. Independente se é praticada uma preservação dos dados ou uma preservação o mais integral o possível da obra de arte, o que estamos preservando é outra memória. Surge uma memória da indústria e sua história de hibridação com o campo artístico, sendo possível constituir até mesmo uma nova disciplina: "história da indústria e a arte".

Mesmo que preservar ao máximo a integralidade da obra de arte digital também não elimine por completo a dimensão industrial que a obra carrega, ao ultrapassar o elemento técnico restrito à preservação como descrição/documentação, permite-se que o acesso ao

${ }^{5}$ Ver, por exemplo, a Revista de Gambiologia Facta (http://www.facta.art.br/), sobretudo a número 3, com o tema "Poética hacker", lançada em abril de 2015.

\begin{tabular}{l|l|l|l|l|l|l|} 
(c) Rev. Digit.Bibliotecon. Cienc. Inf. & Campinas, SP & v.14 & n.3 & p.501-514 & set/dez. 2016 & ISSN 1678-765X \\
\hline
\end{tabular} 
acervo não seja realizado apenas pelo elogio a uma "virtuose" do artista ou grupo de artistas (e seus equipamentos) em se criar uma obra "robusta", "estável" ou qualquer outro adjetivo do campo da performance ou rendimento. Salvo quando esse é o argumento estético perceptível fundamental da obra de arte.

Preservar o mais plenamente a obra de arte digital (incluso suas partes industriais) permite inclusive que se veja - mesmo com a distância temporal - o que a obra é como um fenômeno sensível e experimentado pela percepção. Um fenômeno impactado pelas várias constituições híbridas da própria arte (criação/exposição) e que permitiram um avanço da composição da obra de arte dando a ela uma vida transitória (como arte, como dados informacionais/computacionais, como indústria) e permitindo-a transitar livremente como arte, e como design, como mídia, como meio de comunicação entre as pessoas.

Por entendermos essas conjunturas sociais (econômicas e políticas) é que buscamos aqui, com a ideia de preservação integral, pensar sobre o futuro da obra de uma perspectiva curatológica também plena. Essa é uma perspectiva que não está ligada apenas a guarda/conservação das obras, mas também a sua possibilidade de exposição no futuro buscando dar mais significados e justificativas para sua preservação.

\section{CONSIDERAÇÕES FINAIS OU ANTROPOTÉCNICA E A MÁQUINA DA MEMÓRIA}

Na preservação integral (e também sem ela) há um risco: quando entendemos que a indústria está constituindo uma preservação de sua memória agora em locais que supostamente não são "da indústria" (como os museus, acervos e arquivos), nós temos preservada a memória das máquinas industriais junto aos elementos estéticos que compõem o que consideramos obra de arte. Estamos começando a preservar, a contrapelo, a indústria e suas máquinas (paradigmas, equipamentos, softwares etc. - seja como dados ou plenamente).

Se a humanidade pode ser compreendida em sua história como tal é porque percorreu um caminho de evolução biológica. Essa biologia humana tem uma história - uma história da linhagem humana. Ao produzir um processo de preservação da indústria, estamos preservando e criando uma história da linhagem da máquina. A máquina se torna um sistema fechado muito similar ao sistema vivo humano, estudado por Humberto Maturana (2001), e sua expansão pelo planeta se dá de maneira quase autônoma, próximo do que faz um vírus de computador, como vemos em Jussi Parikka (2006).

Essa outra constituição acontece (está acontecendo) automaticamente ou mesmo naturalmente, como parte da nossa constituição como seres humanos. Ele ocorre a reboque (sic) da história da linhagem humana que se faz a partir de técnicas humanas ou antropotécnicas. Para Peter Sloterdijk, as antropotécnicas são "os procedimentos de exercício, 
físicos e mentais, com os quais os homens das culturas mais díspares têm tentado otimizar seu estado imunológico frente aos vagos riscos da vida e as agudas certezas da morte." (SLOTERDIJK, 2012, p .24, tradução nossa)

Para Fabián Ludueña Romandini, de maneira mais ampla, as antropotécnicas são as:

técnicas pelas quais as comunidades da espécie humana e os indivíduos que as compõem agem sobre sua própria natureza animal com o intuito de criar, expandir, modificar, ou domesticar seu substrato biológico, visando à produção daquilo que a filosofia, em um primeiro momento, e, logo a seguir, as ciências biológicas e humanas se acostumaram a chamar de "homem". (LUDUEÑA ROMANDINI, 2012, p. 9)

Assim, a tecnologia digital, como toda tecnologia criada pelo conhecimento humano, é uma antropotécnica. A cultura digital é uma antropotécnica. A economia política é uma antropotécnica. A partir dessa perspectiva, a preservação da arte digital por meio da guarda de dados (informacionais/computacionais) ou integral é a preservação de uma arte que se encontra em espaço cindido (é e não é diferente das outras coisas do mundo). Como vimos, podemos ensaiar que essa preservação revela um processo antropotécnico que confere à máquina a sua memória.

A máquina criada pelo ser humano também se aprimora, a reboque, na evolução de suas predecessoras. Se antes os computadores ocupavam salas enormes, agora as salas enormes são ocupadas por vários computadores cada vez menores (servidores) ou se acoplam ao nosso corpo (smartband, smartwatch, smartphone) e os vestimos (na computação vestível). Podemos, ainda, habitá-los nas smartcities, onde somos cercados por eles, ou no espaço da casa, com a domótica.

As máquinas - que podem ser considerados equipamentos que "salvam memória" têm o humano trabalhando a seu favor, reconstituindo sua memória subjetiva, afetiva, através deles. Acoplam-se ao ser humano (reboque) e em sua memória habitam (as memórias das máquinas presentes na lembrança que os humanos têm na vivência com elas) ${ }^{6}$.

Escolher preservar as obras apenas como dados, como se viu, é um caminho que parece "natural". É natural por igualar as obras ao restante dos produtos no mundo tal como vem sendo realizado desde o advento da forma mercadoria na economia humana, conforme mostrado por autores como Walter Benjamin (2006) na obra das Passagens, por exemplo, e por Giorgio Agamben (2007) em Estâncias.

\footnotetext{
${ }^{6}$ Cada vez mais criamos memórias de momentos vividos em ligação com outras pessoas do mundo por meio das máquinas que permitem as trocas de mensagens em aplicativos diversos, e-mails etc.. Porém, a presença das máquinas na memória humana é mais concreta quando pensamos o quanto os ambientes tridimensionais de jogos, por exemplo, e as suas narrativas habitam e estimulam os jogadores a criar novas histórias. Assim, as memórias passam a serem criadas no uso das máquinas e contadas entre seres humanos que viveram experiências em jogos de diversas categorias, especialmente MOBA (Multiplayer Online Battle Arena), MMO (Massively Multiplayer Online) e/ou jogos diversos do gênero RPG etc.
}

\begin{tabular}{l|l|l|l|l|l|l|}
\hline (c) Rev. Digit.Bibliotecon. Cienc. Inf. & Campinas, SP & v.14 & n.3 & p.501-514 & set/dez. 2016 & ISSN 1678-765X \\
\hline
\end{tabular}


Por fim, procuramos pensar que talvez seja necessário haver um esforço em prol da preservação integral (ao menos de uma perspectiva estética). Sabemos que o sentido de se conservar as obras apenas como dados faz menos sentido para o campo artístico do que o faz para o campo da Ciência da Informação ou Museologia. Mesmo pensando a partir desses campos, ao ampliar o que se preserva das obras de arte digital não apenas se colabora com o curador das exposições futuras, mas se multiplicam as possibilidades de formação de imagens que a obra em reserva técnica tem. Então, assume-se aqui a perspectiva não dos campos das artes, da ciência da informação ou museologia, mas da própria obra e do retorno dela ao público e sua forma estética, mesmo que essa forma seja outra - emulada, migrada ou recriada.

Assim, a integralidade ou plenitude da preservação digital da arte digital não está na técnica de se preservar além dos dados/documentação (informacional/computacional), mas na intenção do curador/conservador em preservar o que se manifesta como arte. Pensando com Emanuele Coccia (2010), seria uma tentativa de se preservar algo mais próximo do fenômeno que chamamos até aqui de "obra de arte digital" ou "obra de arte tecnológica" em seu todo sensível. Esse esforço genérico pode e deve ser orientado a cada obra que se deseja preservar, tendo em vista que essa obra é, não apenas de "arte", mas juntamente uma obra da "indústria" (nos hardwares e softwares utilizados), uma obra política e econômica e, portanto, uma obra antropotécnica.

\section{REFERÊNCIAS}

AGAMBEN, Giorgio. Estâncias. Trad. de Selvino José Assmann. Belo Horizonte: UFMG, 2007.

BARRETO, Aldo de Albuquerque. Questão da informação. São Paulo em Perspectiva, v. 8, n. 4, 1994.

BENJAMIN, Walter. Passagens. Trad. de Irene Aron e Cleonice P. B. Mourão. Belo Horizonte: UFMG/Imprensa Oficial de São Paulo, 2006.

BENSE, Max. Pequena estética. Trad. de J. Guinsburg e Ingrid Dormien Koudela. São Paulo: Perspectiva, 2003.

CAUQUELIN, Anne. Arte contemporânea: uma introdução. Trad. de Rejane Janowitzer. São Paulo: Martins Fontes, 2005.

COCCIA, Emanuele. A vida sensível. Trad. de Diego Cervelin. Florianópolis: Cultura e Barbárie, 2010.

CRAMER, Florian. What is "post-digital"? A Peer Reviewed Jounal About, vol. 3, issue 1, 2014. Disponível em: <http://www.aprja.net/?p=1318> Acesso em: <10/02/2015>

\begin{tabular}{l|l|l|l|l|l|l|}
\hline (c) Rev. Digit.Bibliotecon. Cienc. Inf. & Campinas, SP & v.14 & n.3 & p.501-514 & set/dez. 2016 & ISSN 1678-765X \\
\hline
\end{tabular}


DANTO, Arthur. O mundo da arte. Artefilosofia, Ouro Preto, n. 1, p. 13-25, jul. 2006.

GASPARETTO, Débora Aita. O "curto-circuito" da arte digital no Brasil. Santa Maria/RS: Ed. do autor, 2014.

GOBIRA, Pablo. A obra de arte computacional e a sua memória: desafios para sua preservação. In: ENCUENTRO LATINOAMERICANO DE BIBLIOTECARIOS, ARCHIVISTAS Y MUSEÓLOGOS ,7., 2015, Valparaíso/Chile. Anais... Valparaíso/Chile: EBAM, 2015.

GOBIRA, Pablo. A preservação da obra de arte digital: reflexões críticas sobre sua efemeridade. In: ENCONTRO NACIONAL DA ANPAP, 23., 2014, Belo Horizonte. Anais... Belo Horizonte: ANPAP, 2014.

GOBIRA, Pablo; CORRÊA, Fernanda. Como preservar a arte computacional? Ações curatoriais para a criação e manutenção de acervos. In: CONGRESSO DO NÚCLEO INTERDISCIPLINAR DE ESTUDOS DA IMAGEM NINFA/UFMG - O Borboletear do Método, 2016, Belo Horizonte. Anais... Belo Horizonte: FAFICH/UFMG, 2016. p.563-573.

GOBIRA, Pablo; MUCELLI, Tadeus (Orgs.). Configurações do pós-digital: arte e cultura tecnológicas. Belo Horizonte: UEMG, 2016. (Prelo)

GOBIRA, Pablo; MUCELLI, Tadeus; PROTA, Raphael. Instabilidade digital: a preservação e a memória da arte digital no contexto contemporâneo. In: ENCONTRO

INTERNACIONAL DE ARTE E TECNOLOGIA, 13., (\#13.ART): arte, política e singularidade, 2014, Brasília. Anais... Brasília: Medialab, 2014.

GROYS, Boris. Camaradas do tempo. Caderno SESC-Videobrasil, São Paulo, n. 6, p. 119$127,2010$.

LA FERNA, Jorge. Arquivos de arte digital - estratégias, metodologias e paradigmas.

Revista Observatório Itaú Cultural, n. 19, São Paulo, Itaú Cultural, p. 77-85, nov./2015 mai./2016.

LUDUEÑA ROMANDINI, Fabián. A comunidade dos espectros. I. Antropotecnia. Trad. de Alexandre Nodari e Leonardo D'Ávila de Oliveira. Desterro, Florianópolis: Cultura e Barbárie, 2012.

MATURANA, Humberto. Cognição, ciência e vida cotidiana. Trad. de Cristina Magro e Victor Paredes. Belo Horizonte: UFMG, 2001.

PARIKKA, Jussi. Antrobsceno. In: GOBIRA, Pablo; MUCELLI, Tadeus (Orgs.).

Configurações do pós-digital: arte e cultura tecnológicas. Belo Horizonte: UEMG, 2016. (Prelo)

PARIKKA, Jussi. A máquina viral universal. Trad. de Luiz Roberto M. Gonçalves. In: BARRETO, Ricardo; PERISSINOTTO, Paula (Orgs.). FILE: Festival Internacional de Linguagem Eletrônica. São Paulo: FILE, 2006.

\begin{tabular}{l|l|l|l|l|l|l|}
\hline (c) Rev. Digit.Bibliotecon. Cienc. Inf. & Campinas, SP & v.14 & n.3 & p.501-514 & set/dez. 2016 & ISSN 1678-765X \\
\hline
\end{tabular} 
SANTAELLA, Lucia. Temas e dilemas do pós-digital: a voz da política. São Paulo: Paulus, 2016.

SLOTERDIJK, Peter. Has de cambiar tu vida. Valência: Editorial Pre-Textos, 2012.

\section{AGRADECIMENTOS}

Agradecemos à FAPEMIG, ao CNPq e à Pró-Reitoria de Pesquisa e Pós-Graduação da UEMG pelo apoio aos projetos do Laboratório de Poéticas Fronteiriças (http://labfront.tk) dos quais este trabalho resulta e à Fernanda Corrêa pelas traduções do resumo deste trabalho.

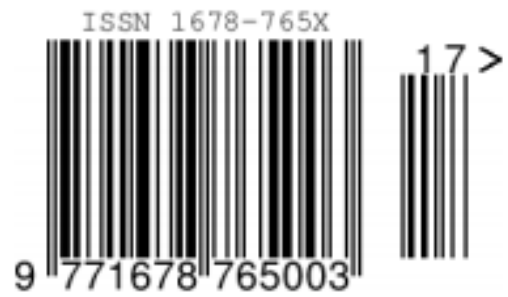

